\title{
Prevalence and income-related equity in hypertension in rural China from 1991 to 2011: differences between self-reported and tested measures
}

Dan Cao', Zhongliang Zhou ${ }^{1 *}$, Yafei $\mathrm{Si}^{1}$, Xiao Xiao ${ }^{1}$, Xiao Wang ${ }^{2}$, Chi Shen ${ }^{1}$, Yangling Ren ${ }^{1}$, Min Su', Shuyi He ${ }^{2}$ and Jianmin $\mathrm{GaO}^{1}$

\begin{abstract}
Background: Along with economic growth and living standard improvement, hypertension has become one of the most prevalent chronic diseases in China. Self-reported measures and tested measures of hypertension may differ significantly due to the low awareness of prevalence. The objective of this study is to figure out whether and how selfreported measures differ from tested measures in terms of prevalence and equity.

Method: We have used data from the China Health and Nutrition Survey database from 1991 to 2011 and extracted the data of rural areas using hukou system. Hypertension is categorized into two groups: self-reported hypertension and tested hypertension. To evaluate the equity of self-reported hypertension and tested hypertension, we calculated their Concentration Index (C) and decomposed $\mathrm{C}$ based on which we have obtained the horizontal-inequity index $(\mathrm{HI})$ of each year. Probit Model was deployed to analyze the key determinants of hypertension prevalence.

Results: We found that the prevalence of both self-reported hypertension and tested hypertension have sharply increased from 1991 to 2011 in rural China and the population of tested hypertension was significantly larger than that of self-reported hypertension. For self-reported hypertension, prevalence rate increased from 2.72 to $13.2 \%$ and for tested hypertension it increased from 11.01 to $25.05 \%$. Both of the Concentration Index (C) and horizontal-inequity index $(\mathrm{HI})$ of self-reported hypertension and tested hypertension appeared to be contradictory. The $\mathrm{C}$ and $\mathrm{HI}$ of self-reported hypertension in 2011 were 0.032 and 0.060 respectively while the $\mathrm{C}$ and $\mathrm{HI}$ of tested hypertension were -0.024 and -0.015 respectively.
\end{abstract}

Conclusion: More efforts should be put into for improving the poor's health, especially in equal access to health services. Symptom-based measures such as tested hypertension should be adopted more widely in empirical studies.

Keywords: Tested hypertension, Self-reported hypertension, Equity, Concentration index

\section{Background}

Chronic diseases, such as cardiovascular and cerebrovascular diseases, are becoming increasingly prevalent [1] and hypertension is one of the most prevalent but preventable one amongst them [2]. The number of adults with hypertension in 2025 is predicted to be 1.56 billion and the total number of them in developing countries is

\footnotetext{
* Correspondence: zzliang1981@163.com

${ }^{1}$ School of Public Policy and Administration, Xi'an Jiaotong University, Xi'an,

People's Republic of China

Full list of author information is available at the end of the article
}

substantially higher than developed countries [3]. Despite of the great economic growth, since the reform and opening-up policy was implemented, one of the most alarming issue is that the morbidity rate of hypertension has increased from $1.19 \%$ in 2003 to $9.89 \%$ in 2013 [4, 5]. Although prior studies have proved that a substantial health inequity exists not only in China but also in other countries [6-9]. This issue in China has to be addressed rigorously since the new objective of "healthy China" has been put forward in the National Health Conference in 2016. Also, hypertension burden appeared differently in

(c) The Author(s). 2019 Open Access This article is distributed under the terms of the Creative Commons Attribution 4.0 International License (http://creativecommons.org/licenses/by/4.0/), which permits unrestricted use, distribution, and 
rural and urban areas in China [10, 11]. In 2012, the hypertension cases in China had reached up to 266 million [12], yet the prevalence of hypertension remains inflating, whereas the awareness, treatment and control of hypertension remained at a inadequate especially in the rural areas [13]. Several studies have stressed that the population of hypertension in rural China has increased rapidly. In the last decades, the growth of hypertension in rural China was higher than that in urban areas and the prevalence in rural areas nearly reached the same level in urban areas [14, 15]. Recently, researchers were even found that rural residents have higher hypertension prevalence than urban residents in Southwest China [16].

Socioeconomic differences in chronic disease prevalence have been found worldwide. For instance, previous studies have proved that socioeconomic inequalities exist among patients with some fatal chronic diseases, such as cancer and heart diseases [9]. A study focusing on the chronic diseases in Slovenia also suggests that the prevalence is significantly higher in the population with lower socioeconomic and employment status [17]. Moreover, the relationship between hypertension prevalence and several potentially modifiable factors such as education, profession and income level have been studied [18, 19]. Over the last decades, previous researchers have agreed on that the socioeconomic status can significantly affect hypertension prevalence and the severity of hypertension [10]. A related study also shows the same result that lower education is associated with a higher risk of prehypertension [20].

China has started equalizing the basic public health services since 2009, granting sufficient access to basic public health services [21]. Thus hypertension management was improved substantially from 2008 to 2012 and the inequity across regions declined over time [22]. Access to some services such as chronic diseases screening is still far away from being equalized. Regardless of significant improvement in coverage of basic public health services, more equalization needs to be improved [23]. Unbalanced access and utilization results in uneven awareness and thus it is generally recognized that wealthier people have more opportunities to become aware of the prevalence of chronic diseases. Researchers usually use two measures to evaluate hypertension prevalence: self-reported prevalence and tested prevalence. These two measures may differ a lot due to the uneven awareness of hypertension prevalence. The disparity between the poor and the rich may lead to a biased result and mislead the government to implement related policies [24]. Researchers have also found that self-reported measures can lead to significant deviation from the real prevalence and inequality, and using symptom-based measures can be an effective way to eliminate the reporting bias $[25,26]$.
To find out whether and how self-reported measures differ from tested measures, we conducted this study. In this study, we extracted the rural data from a national representative database-- the China Health and Nutrition Surveys from 1991 to 2011 using the hukou system. We deployed both of these two methods to measure hypertension: one is self-reported hypertension and the other is tested hypertension namely symptom-based. Concentration index was adopted to estimate inequity. Previous literature has addressed that unequal access to health care utilization may cause a prevalence deviation between selfreported measures and tested measures. Self-reported measure causes an underestimation of real prevalence, especially for those with low socioeconomic status. Hence, in this study, we hypothesize that both the prevalence and the equity of self-reported and tested measures differ a lot.

\section{Methods}

\section{Data sources}

We used a national representative database from China Health and Nutrition Surveys (CHNS). CHNS is a longitudinal survey from the late 1980s conducted by the University of North Carolina Center for Population Studies, the National Institute of Nutrition and Food Safety and the China's Center for Disease Control. The CHNS data contains new household formation, replacement communities and households, and all household members [27]. The questionnaire contains 12 dimensions: population density, economic activity, traditional markets, modern markets, transportation infrastructure, sanitation, communications, housing, education, diversity, health infrastructure and social services.

CHNS survey covers nine provinces that vary substantially in geography, economic level, public resources and health indicators. The samples in each province were selected with a multistage, random cluster process. The counties were stratified by income (low, middle and high) in each province and a weighted sampling scheme was used to select four counties randomly. Villages and towns within the counties and urban and suburban neighborhoods within the cities were chosen randomly. Approximately there were 4400 households in the whole survey covering 19,000 individuals [28].

The CHNS contains a weakness; the follow-ups were missing some chunks of data every year. There were three major reasons: 1) missing population that couldn't be found because of travel, hours of work or play, 2) school children who were in boarding schools, 3) migrants work for working population. But the CHNS considered loss follow-ups into their design and recruited new participants as replenishment population if there were no more than 20 households or if respondents had constituted a new family [29]. This design of replenishment sample made up the weakness caused by the loss of enrolled 
subjects. The cross sectional data of each wave was regarded as national representative in many other researches [30-32].

\section{Measures/variables \\ Dependent variables}

The design of this study contains two dependent variables: tested prevalence and self-reported prevalence. For the tested prevalence, the CHNS measured respondent's blood pressure three times and we took their average value. We established the database of tested hypertensive persons whose SBP (systolic blood pressure) were higher than $140 \mathrm{mmHg}$ and their DBP (diastolic blood pressure) were higher than $90 \mathrm{mmHg}$. Self-reported hypertensive persons were classified as; who knew they were suffering from high blood pressure or taking any anti-hypertension drugs by answering the questions: "Have you ever been diagnosed with hypertension by a doctor?" or "Are you currently taking any antihypertensive medication?"

\section{Independent variables}

According to prior studies, we adopted age, gender, BMI, economic level, smoking, drinking, schooling, marital status, region and physical examinations of the past 4 weeks [33]. The economic level in this study was defined by grouping inflation to 2011 household income per capita into five cohorts: the poorest, the poorer, the middle, the richer and the richest. If the respondent has smoked even once, the person is classified as a Smoker. Also if the respondent drinks any form of alcohol for more than 3 times a week, the person is classified as Drinker. Regions are categorized into three: east, middle and west, which are consistent with the standard in Statistic Book of PRC. More details about independent variables are presented in Table 1.

All independent variables are grouped into unavoidable variables and avoidable variables. The unavoidable variables refer to factors that couldn't be avoided in hypertension including age and gender, while avoidable variables contain economic level, smoking history, drinking history, physical examinations of the past 4 weeks, region, schooling, BMI and marital status [34, 35].

\section{Measure of equity}

The feasibility and reliability for Concentration $\operatorname{Index}(C)$ and decomposition of $\mathrm{C}$ to measure health equity have been well documented [36, 37]. The concentration index can expose the relationship between health outcomes, such as self-reported health status and living standards like income level and wealth index. More widely, the concentration index can examine inequality not only in health outcomes but also in any health sector variable of interest [38], such as hypertension prevalence in this
Table 1 Independent Variables

\begin{tabular}{|c|c|c|c|}
\hline \multicolumn{2}{|c|}{ Unavoidable variables } & \multicolumn{2}{|l|}{ Avoidable variables } \\
\hline Name & Explanation & Name & Explanation \\
\hline Agegroup & $\begin{array}{l}18 \sim 45^{a}=0 \\
46 \sim 59=1 \\
60 \text { and above }=2\end{array}$ & Economic level & $\begin{array}{l}\text { The poorest }^{a}=0 \text { The } \\
\text { poorer }=1 \\
\text { The middle }=2 \text { The } \\
\text { richer }=3 \\
\text { The richest }=4\end{array}$ \\
\hline \multirow[t]{7}{*}{ Gender } & $\begin{array}{l}\text { Male }^{a}=0 \\
\text { Female }=1\end{array}$ & Smoking & $\mathrm{No}^{\mathrm{a}}=0 \mathrm{Yes}=1$ \\
\hline & & Drinking & $\begin{array}{l}\text { Less than } 3 \text { times } \\
\text { a week }{ }^{a}=0 \\
\text { More than } 3 \text { times } \\
\text { a week }=1\end{array}$ \\
\hline & & $\begin{array}{l}\text { Have physical } \\
\text { examination in the } \\
\text { past } 4 \text { weeks }\end{array}$ & $\mathrm{No}^{\mathrm{a}}=0 \mathrm{Yes}=1$ \\
\hline & & Region & $\begin{array}{l}\text { East }^{a}=0 \text { Middle }=1 \\
\text { West }=2\end{array}$ \\
\hline & & Schooling & $\begin{array}{l}\text { Illiteracy }{ }^{a}=0 \\
\text { Primary and junior } \\
\text { high school = } 1 \\
\text { High and technical } \\
\text { secondary school = } 2 \\
\text { Junior college and } \\
\text { above }=3\end{array}$ \\
\hline & & $\mathrm{BMI}$ & $\begin{array}{l}\mathrm{BMI}<18.5^{\mathrm{a}}=0 \\
18.5 \leq \mathrm{BMI}<24=1 \\
24 \leq \mathrm{BMI}<28=2 \\
\mathrm{BMI} \geq 28=3\end{array}$ \\
\hline & & Marital status & $\begin{array}{l}\text { Unmarried }^{\mathrm{a}}=0 \\
\text { Married }=1 \\
\text { Others }=2\end{array}$ \\
\hline
\end{tabular}

${ }^{a}$ is the control group of dummy variables

article. In our study, the two key variables underlying the concentration index are hypertension prevalence, the distribution of which is the subject of interest, and income level against which the distribution is to be assessed. We can see the degree of inequality of the hypertension prevalence distributes among different living standards. Further more, we decomposed the $\mathrm{C}$ to figure out how such inequality can be explained. The following specifically shows how we computed $\mathrm{C}$ and sub-section 2.4 decomposition of $\mathrm{C}$.

\section{Concentration index}

In general, the Concentration Index $(\mathrm{C})$ is considered to be a good indicator reflecting inequality in health status caused by socioeconomic factors $[35,39]$. In this study, we used the concentration index to measure the inequality of hypertension prevalence of people in different income groups. The range of the concentration index is from -1 to 1 . If people with different economic levels have the same probability to suffer from hypertension, the concentration index equals to 0 . If the concentration index is negative, it indicates hypertension prevalence is pro-poor and if the concentration index is positive, it indicates 
hypertension prevalence is pro-rich. We calculated the concentration index with the equation below:

$$
\mathrm{C}=\frac{2}{\mu} \operatorname{cov}\left(y, R_{i}\right)
$$

Where $R_{i}$ represents the proportion of individual $i$ in sample sorted by economic level (inflated to 2011 per capita household income), $y_{i}$ is hypertension prevalence, $\mu$ represents the average of hypertension prevalence.

\section{Measures of horizontal inequity}

\section{Decomposition of concentration index}

Decomposition of concentration index can provide a reliable way to analyze the contribution of various factors to the inequality of hypertension by estimating each factor's effect on hypertension prevalence using a Probit model [40]. The Probit equation is as below.

$$
\operatorname{Pr}(\mathrm{Y}=1 \mid \mathrm{X})=\varnothing\left(\mathrm{X}^{\prime} \beta\right),
$$

Where $\mathrm{Pr}$ is the probability of suffering from hypertension, $\varnothing$ represents the cumulative function of the normal distribution, $\beta$ is the parameter evaluated by maximum likelihood method.

After decomposing the concentration index into the contribution of various factors to the inequality of hypertension and summing up the C's of all avoidable variables, we obtained the horizontal inequity of hypertension prevalence, of which the unavoidable variables contained demographic variables and prevalence variables, and the avoidable variables contained economic level, risk behaviors of hypertension and other avoidable variables. In this study, we decomposed both the C's of tested prevalence and self-reported prevalence of each year.

We estimated each factor's effect on hypertension prevalence by the model below:

$$
y_{i}=\alpha^{m}+\sum_{j} \beta_{j}^{m} x_{j i}+\sum_{k} \gamma_{k}^{m} z_{k i}+\mu_{i},
$$

Where $y_{i}$ represents the dependent variable, $x_{j i}$ represents the unavoidable variable, and $z_{k i}$ is the avoidable variable, $\beta_{j}^{m}$ and $\gamma_{k}^{m}$ represent the partial effects, $\mu_{i}$ is the residual term.

The concentration index formula for the horizontal inequity is presented as below:

$$
C=\sum_{j}\left(\beta_{j}^{m} x_{j i} / \mu\right) C_{j}+\sum_{k}\left(\gamma_{k}^{m} z_{j i} / \mu\right) C_{k}+\frac{G C_{k}}{\mu_{i}},
$$

Where $\mathrm{C}$ represents the concentration index of hypertension prevalence, $C_{j}$ represents the concentration index of $x_{j}, C_{k}$ is the concentration index of $z_{k}, G C_{k}$ is the concentration index of residual terms. This formula indicates that the concentration index of hypertension prevalence is obtained by adding weight-sum of avoidable variables' and unavoidable variables' C's. Furthermore, the horizontal-inequity index can be measured by controlling the contribution of the unavoidable variables.

\section{Results}

\section{Descriptive results of 2011}

Excluding respondents under 18 and singular values we have a sample of 122,945 observations. The sample values contain 11,119 in $1991,10,828$ in $1993,11,891$ in 1997 , 13,324 in $2000,13,194$ in $2004,15,922$ in $2006,16,313$ in 2009 and 19,722 in 2011 respectively. The descriptive results of our sample are presented in Table 2. A table about baseline subjects involved in 1991 and new subjects of each wave is shown in the (Additional file 1: Table S1).

\section{Comparison of prevalence rate}

Figure 1 displays the prevalence rate of self-reported hypertension and tested hypertension, which suggests that the prevalence rate of self-reported hypertension in rural China has been increasing from 1991 (2.72\%) to 2011 (13.2\%). The prevalence of tested hypertension in rural China also has increased from 11.01\% in 1991 to $25.05 \%$ in 2011. The increasing trend of self-reported prevalence and tested prevalence appears consistent. Figure 1 also indicates that the morbidity rate of selfreported hypertension increased more rapidly after 2000 .

Considering the age of follow-ups would increase across the time, this study also evaluated the age-adjusted prevalence of both self-reported and tested hypertension. Both the prevalence's, self-reported and tested hypertension, was adjusted to age distribution of the corresponding year in order correct the prevalence deviation caused by the follow-up getting older across time. The results of ageadjusted prevalence are placed in the [Additional file 2: Figure S1]. Additionally, to guarantee the hypertension screening in this survey would not affect the self-reported prevalence, identified baseline subjects and new subjects of each year and conducted Chi-Squared test. The null hypothesis was that the respondent's self-reported hypertension status was independent of the respondent being in baseline population or new population. The results of Chi-Squared test suggested that the prevalence of two kinds of respondents varied in some years, but had no significant difference in most years, which is shown in the [Additional file 3: Table S2]. The results confirmed that hypertension screening across time has little effect on selfreported hypertension prevalence.

\section{Comparison of equity Concentration index}

In this study, we used the concentration index to measure the inequality of hypertension prevalence of people with different income groups. The concentration indexes of 
Table 2 Descriptive results (\%)

\begin{tabular}{|c|c|c|c|c|c|c|c|c|c|}
\hline & & 1991 & 1993 & 1997 & 2000 & 2004 & 2006 & 2009 & 2011 \\
\hline \multirow[t]{3}{*}{ Agegroup } & $18 \sim 45$ & 66.41 & 65.40 & 61.73 & 58.88 & 54.11 & 59.49 & 56.29 & $\overline{51.72}$ \\
\hline & $46 \sim 59$ & 17.89 & 18.17 & 20.40 & 23.05 & 25.40 & 21.39 & 22.85 & 25.07 \\
\hline & 60 and above & 15.69 & 16.43 & 17.86 & 18.07 & 20.50 & 19.12 & 20.86 & 23.21 \\
\hline \multirow[t]{4}{*}{ BMI } & $<18.5$ & 10.26 & 9.02 & 8.02 & 6.78 & 6.26 & 6.09 & 6.53 & 4.99 \\
\hline & $18.5 \sim 24$ & 71.14 & 70.40 & 65.92 & 60.97 & 57.85 & 56.86 & 53.81 & 50.47 \\
\hline & $24 \sim 28$ & 15.56 & 17.46 & 20.95 & 25.42 & 27.73 & 28.69 & 30.04 & 32.49 \\
\hline & $>28$ & 3.04 & 3.13 & 510 & 6.84 & 8.06 & 8.36 & 9.62 & 12.05 \\
\hline \multirow[t]{4}{*}{ Schooling } & Illiterate & 24.03 & 21.90 & 18.11 & 16.37 & 12.26 & 14.36 & 12.50 & 9.85 \\
\hline & Primary or junior high school & 60.11 & 61.60 & 62.41 & 62.50 & 62.87 & 58.20 & 61.98 & 57.20 \\
\hline & High school or technical secondary school & 13.39 & 13.91 & 16.54 & 17.19 & 19.97 & 20.89 & 19.32 & 22.66 \\
\hline & Junior college and above & 2.47 & 2.59 & 2.94 & 3.93 & 4.91 & 6.54 & 6.20 & 10.29 \\
\hline \multirow[t]{3}{*}{ Marital status } & Unmarried & 18.37 & 18.37 & 18.33 & 17.92 & 9.16 & 7.42 & 6.84 & 5.96 \\
\hline & Married & 75.46 & 74.61 & 74.58 & 75.09 & 82.06 & 83.94 & 82.94 & 83.64 \\
\hline & Others & 6.76 & 7.01 & 7.09 & 6.99 & 8.78 & 10.23 & 10.23 & 10.40 \\
\hline \multirow[t]{3}{*}{ Region } & West & 33.67 & 32.86 & 24.01 & 32.24 & 31.16 & 30.84 & 29.87 & 36.62 \\
\hline & Middle & 52.34 & 52.68 & 61.37 & 55.04 & 56.31 & 55.26 & 56.72 & 46.75 \\
\hline & East & 13.99 & 14.46 & 14.62 & 12.73 & 12.54 & 13.90 & 13.41 & 16.63 \\
\hline \multirow[t]{2}{*}{ Gender } & Male & 48.63 & 48.84 & 48.97 & 48.86 & 48.94 & 47.26 & 46.74 & 47.00 \\
\hline & Female & 51.37 & 51.16 & 51.03 & 51.14 & 51.06 & 52.74 & 53.26 & 53.00 \\
\hline \multirow[t]{2}{*}{ Smoking } & Yes & 35.07 & 33.98 & 31.90 & 31.52 & 32.58 & 31.53 & 31.35 & 30.66 \\
\hline & No & 64.93 & 66.02 & 68.10 & 68.48 & 67.42 & 68.47 & 68.65 & 69.34 \\
\hline \multirow[t]{2}{*}{ Drinking } & Yes & 37.86 & 35.61 & 35.99 & 35.24 & 32.90 & 31.89 & 33.25 & 33.92 \\
\hline & No & 62.14 & 64.39 & 64.01 & 64.75 & 67.10 & 68.11 & 66.75 & 66.08 \\
\hline \multirow[t]{2}{*}{ Physical examination } & Yes & 1.03 & 0.92 & 0.91 & 0.83 & 3.44 & 3.36 & 4.00 & 7.26 \\
\hline & No & 98.97 & 99.08 & 99.09 & 99.17 & 96.56 & 96.64 & 96.00 & 92.74 \\
\hline
\end{tabular}

self-reported hypertension from 1991 to 2011 are presented in Table 3.

It is evident that the concentration indexes of selfreported hypertension from 1991 to 2011 are all positive and statistically significant in most of the years. Nonetheless, when tested hypertension is included, the concentration indexes present the opposite bias. In addition, the concentration indexes of tested hypertension for the most years indicate an opposite trend, for example, -0.003 [95\%CI $(-0.043,0.038)]$ in $1993,-0.008$ [95\%CI $(-0.040,0.025)]$ in $1997,-0.030$ [95\%CI $(-0.058,-0.001)$ ] in 2006, and -0.024 [95\% CI $(-0.047,-0.00009)$ ] in 2011.

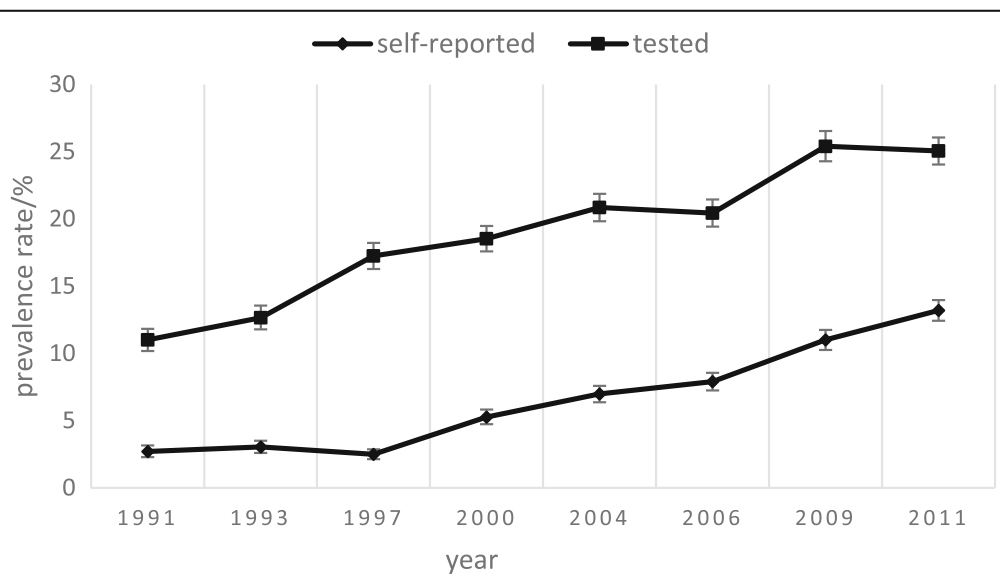

Fig. 1 The prevalence of self-reported hypertension and tested hypertension 
Table 3 Concentration Index from 1991 to 2011

\begin{tabular}{|c|c|c|c|c|c|c|}
\hline \multirow[t]{2}{*}{ Year } & \multicolumn{3}{|c|}{ Self-reported hypertension } & \multicolumn{3}{|c|}{ Tested hypertension } \\
\hline & $C$ & $95 \% \mathrm{Cl}$ & & $C$ & $95 \% \mathrm{Cl}$ & \\
\hline 1991 & 0.118 & 0.023 & 0.213 & 0.088 & 0.044 & 0.132 \\
\hline 1993 & 0.144 & 0.055 & 0.232 & -0.003 & -0.043 & 0.038 \\
\hline 1997 & 0.064 & -0.020 & 0.148 & -0.008 & -0.040 & 0.025 \\
\hline 2000 & 0.052 & -0.008 & 0.112 & 0.010 & -0.020 & 0.040 \\
\hline 2004 & 0.110 & 0.058 & 0.161 & 0.031 & 0.002 & 0.059 \\
\hline 2006 & 0.119 & 0.071 & 0.168 & -0.030 & -0.058 & -0.001 \\
\hline (n) & 0.065 & 0.026 & 0.104 & 0.006 & -0.020 & 0.032 \\
\hline 2011 & 0.032 & -0.002 & 0.065 & -0.024 & -0.047 & -0.00009 \\
\hline
\end{tabular}

Therefore, tested hypertension is not pro-rich, instead pro-poor in these years. Table 3 also indicates that the concentration indexes are getting closer to 0 since 2009, that might be due to the start of basic public services equalization in 2009.

\section{Decomposition of concentration index}

Probit Model was adopted in this study to analyze the effects of independent variables on hypertension prevalence. Taking decomposition results of year 2011 in Table 4 as an example, controlling for confounding variables compared to those under 45, people with older age have more probability to have both tested hypertension and self-reported hypertension. Decomposition results of other years are presented in the [Additional file 4: Table S3-S4]. In 2011, the difference between people underweight and people with higher BMI is statistically significant suggesting that the latter are more likely to get hypertension (either based on tested hypertension or self-reported hypertension). People with higher education level have a lower probability of tested hypertension compared with people who are illiterate. The results of self-reported hypertension are not so statistically significant. Compared to unmarried, married people are more likely to suffer from hypertension.

Table 4 The regression results of 2011

\begin{tabular}{|c|c|c|c|c|c|c|c|c|c|c|c|c|}
\hline & \multicolumn{6}{|c|}{ Self-reported hypertension } & \multicolumn{6}{|c|}{ Tested hypertension } \\
\hline & $d y / d x$ & Std. Err & $\begin{array}{l}\text { Demand } \\
\text { elasticity }\end{array}$ & C & Contribution & $\%$ & $d y / d x$ & Std. Err & $\begin{array}{l}\text { Demand } \\
\text { elasticity }\end{array}$ & C & Contribution & $\%$ \\
\hline The poor & -0.011 & 0.010 & -0.017 & -0.400 & 0.007 & 20.9 & 0.002 & 0.016 & 0.001 & -0.400 & -0.001 & 2.4 \\
\hline The middle & 0.010 & 0.011 & 0.015 & 0.001 & 0.000 & 0.03 & 0.025 & 0.017 & 0.020 & 0.001 & 0.000 & -0.1 \\
\hline The richer & 0.004 & 0.011 & 0.006 & 0.401 & 0.003 & 8.1 & -0.024 & 0.016 & -0.020 & 0.401 & -0.008 & 34 \\
\hline The richest & 0.008 & 0.011 & 0.012 & 0.801 & 0.010 & 30.4 & -0.019 & 0.016 & -0.015 & 0.801 & -0.012 & 52.6 \\
\hline $46 \sim 59$ & $0.138^{c}$ & 0.013 & 0.262 & 0.081 & 0.021 & 67.3 & $0.189^{c}$ & 0.015 & 0.190 & 0.081 & 0.015 & -66.6 \\
\hline 60 and above & $0.281^{c}$ & 0.017 & 0.493 & -0.127 & -0.063 & 197.5 & $0.335^{c}$ & 0.017 & 0.312 & -0.127 & -0.040 & 170.4 \\
\hline $18.5 \leq \mathrm{BMI}<24$ & $0.043^{b}$ & 0.018 & 0.165 & -0.010 & -0.002 & -5.2 & $0.120^{c}$ & 0.027 & 0.243 & -0.010 & -0.002 & 10.4 \\
\hline $24 \leq \mathrm{BMI}<28$ & $0.131^{c}$ & 0.026 & 0.323 & 0.031 & 0.010 & 31.5 & $0.274^{c}$ & 0.033 & 0.357 & 0.031 & 0.011 & -47.6 \\
\hline $\mathrm{BMI} \geq 28$ & $0.258^{c}$ & 0.041 & 0.236 & 0.025 & 0.006 & 18.3 & $0.444^{c}$ & 0.038 & 0.215 & 0.025 & 0.005 & -22.7 \\
\hline $\begin{array}{l}\text { Primary and junior } \\
\text { high school }\end{array}$ & -0.005 & 0.010 & -0.022 & -0.028 & 0.001 & 2.0 & $-0.038^{b}$ & 0.016 & -0.087 & $-\overline{0.028}$ & 0.002 & -10.6 \\
\hline $\begin{array}{l}\text { High school or technical } \\
\text { secondary school }\end{array}$ & -0.013 & 0.013 & -0.023 & 0.125 & -0.003 & -9.1 & $-0.075^{c}$ & 0.018 & -0.068 & 0.125 & -0.009 & 36.8 \\
\hline $\begin{array}{l}\text { Junior college and } \\
\text { above }\end{array}$ & -0.028 & 0.021 & -0.022 & 0.152 & -0.003 & -10.5 & $-0.067^{a}$ & 0.032 & -0.028 & 0.152 & -0.004 & 18.1 \\
\hline Married & $0.072^{b}$ & 0.020 & 0.453 & 0.016 & 0.007 & 22.6 & 0.047 & 0.031 & 0.159 & 0.016 & 0.003 & -10.8 \\
\hline Other status & $0.156^{c}$ & 0.072 & 0.123 & -0.177 & -0.022 & -68.8 & $0.103^{b}$ & 0.045 & 0.043 & -0.177 & -0.008 & 32.6 \\
\hline The middle region & $-0.030^{c}$ & 0.007 & -0.105 & -0.109 & 0.011 & 36.0 & $-0.033^{c}$ & 0.016 & -0.061 & -0.109 & 0.007 & -28.8 \\
\hline The western region & $-0.047^{c}$ & 0.008 & -0.059 & -0.147 & 0.009 & 27.4 & $-0.035^{b}$ & 0.014 & -0.023 & -0.147 & 0.003 & -14.7 \\
\hline Smoking & 0.005 & 0.010 & 0.010 & 0.008 & 0.000 & 0.3 & 0.006 & 0.014 & 0.007 & 0.008 & 0.001 & -0.3 \\
\hline Female & 0.013 & 0.010 & 0.052 & -0.027 & -0.001 & -4.5 & $-0.047^{c}$ & 0.014 & -0.101 & -0.027 & 0.003 & -11.9 \\
\hline Drinking & 0.010 & 0.010 & 0.007 & 0.142 & 0.001 & 3.1 & $0.046^{c}$ & 0.016 & 0.017 & 0.142 & 0.002 & -10.3 \\
\hline $\begin{array}{l}\text { Having physical } \\
\text { examination }\end{array}$ & $0.102^{c}$ & 0.020 & 0.056 & 0.120 & 0.007 & 21.1 & 0.023 & 0.022 & 0.007 & 0.120 & 0.001 & -3.4 \\
\hline $\mathrm{N}$ & 7124 & & & & & & 7003 & & & & & \\
\hline $\mathrm{R}^{2}$ & 0.1691 & & & & & & 0.1357 & & & & & \\
\hline
\end{tabular}

$\mathrm{a}, \mathrm{b}, \mathrm{c}:$ significantly different from zero at the $0.1,0.05$ and 0.01 level, respectively 
People living in Middle and West China have more probability to get hypertension. Females are less likely to suffer from tested hypertension compared to males, which is opposite to the results of self-reported hypertension but not statistically significant. Drinking is also a risk factor of tested hypertension but not self-reported hypertension. Those who had a physical examination in the past 4 weeks are more likely to have self-reported hypertension.

According to the decomposition results of 2011, considering only one variable effect on hypertension by controlling other factors, the prevalence of hypertension will be concentrated on the rich if the contribution is positive, otherwise, the prevalence of hypertension will be concentrated on the poor. Excluding the total contribution of all variables from the concentration index of hypertension, we obtain the contribution of unexplained variables. In Table 4 it is apparent that in the rural area the prevalence of self-reported hypertension in 2011 can be explained mainly by aged 45 59(67.3\%), aged 60 and above (197.5\%) and other marital status $(-68.8 \%)$. While the prevalence of tested hypertension can be explained mainly by the richest (52.6\%), aged 45 59 (66.6\%) and aged 60 and above (170.4\%).

We calculated the horizontal-inequity indexes of the two hypertension groups from 1991 to 2011. As presented in Table 5, the horizontal-inequity indexes of self-reported hypertension are positive in all 8 years and are statistically significant in most years, while the indexes of tested hypertension are negative in some years, such as -0.004 in 1993, -0.028 in $1997,-0.002$ in $2000,-0.033$ in 2006, -0.009 in 2009 and -0.015 in 2011. Although the horizontal-inequity indexes of tested hypertension are not statistically significant in some years, but they still show clear differences compared with horizontal-inequity indexes of self-reported hypertension.

\section{Sensitivity analysis}

To build the confidence in our concentration index results, we excluded the results whose income level ranks the first $1 \%$ and the last $1 \%$ in our sample and calculated the concentration indexes of 8 years again. Table 6 shows the results of our sensitivity analysis. The table suggests that after exclusion of extreme data, the concentration indexes were consistent with the former results. Beyond that, the trend of 8 years in altered sample was also identical with the trend in the original sample.

In addition, to find out whether the new subjects of each wave would affect signs of concentration index of tested hypertension prevalence in total sample, we also conducted the Cs of baseline subjects in each wave and compared them with Cs of total population. The results are shown in the [Additional file 5: Table S5]. It is apparent that the signs of $\mathrm{Cs}$ of baseline subjects in each wave were generally consistent with signs of total population and the $95 \%$ CIs overlap in each year.

\section{Discussion}

\section{The prevalence of self-reported hypertension and tested hypertension}

We computed separately self-reported prevalence and tested prevalence from 1991 to 2011 in this article. Consistent with those studies, we find that the prevalence of both self-reported hypertension and tested hypertension have rapidly increased from 1991 to 2011 in rural China. This rapid increase may be because of the change of health behaviors in rural China. Overweight rose from 15.56 to $32.49 \%$, and obesity raised from 3.04 to $12.05 \%$. The role that obesity plays in hypertension prevalence has already been discussed in other literatures [41]. Our study emphasizes on this opinion and verifies that obesity in China has a rapid grow in the past decades. The population with tested hypertension was always significantly larger than that with self-reported hypertension [40]. The rise of self-reported prevalence is from 2.72 to $13.2 \%$ from 1991 to 2011, while the tested is from 11.01 to $25.05 \%$. However, compared with prior studies, we found a lower prevalence of both self-reported hypertension and tested hypertension in rural China and a possible reason is that the new subjects of each year may drag the prevalence rate

Table 5 Horizontal-inequity of the two hypertension groups from 1991 to 2011

\begin{tabular}{|c|c|c|c|c|c|c|c|c|c|c|}
\hline \multirow[t]{2}{*}{ Year } & \multicolumn{5}{|c|}{ Self-reported hypertension } & \multicolumn{3}{|c|}{ Tested hypertension } & \multirow[b]{2}{*}{$95 \% \mathrm{Cl}$} & \\
\hline & $\bar{C}$ & Contribution of unavoidable variables & $\mathrm{HI}$ & $95 \% \mathrm{Cl}$ & & $\bar{C}$ & Contribution of unavoidable variables & $\mathrm{HI}$ & & \\
\hline 1991 & 0.118 & 0.100 & 0.018 & -0.007 & 0.113 & 0.088 & 0.020 & 0.068 & 0.024 & 0.112 \\
\hline 1993 & 0.144 & 0.005 & 0.139 & 0.050 & 0.227 & -0.003 & 0.001 & -0.004 & -0.004 & 0.037 \\
\hline 1997 & 0.064 & 0.009 & 0.055 & -0.029 & 0.139 & -0.008 & 0.020 & -0.028 & -0.060 & 0.005 \\
\hline 2000 & 0.052 & 0.013 & 0.039 & -0.021 & 0.099 & 0.010 & 0.012 & -0.002 & -0.032 & 0.028 \\
\hline 2004 & 0.110 & 0.012 & 0.098 & 0.046 & 0.149 & 0.031 & 0.025 & 0.016 & -0.023 & 0.034 \\
\hline 2006 & 0.119 & -0.024 & 0.143 & 0.095 & 0.192 & -0.030 & 0.003 & -0.033 & -0.061 & -0.004 \\
\hline 2009 & 0.065 & 0.008 & 0.057 & 0.018 & 0.096 & 0.006 & 0.015 & -0.009 & -0.035 & 0.017 \\
\hline 2011 & 0.032 & -0.028 & 0.060 & 0.026 & 0.093 & -0.024 & -0.009 & -0.015 & -0.038 & 0.009 \\
\hline
\end{tabular}


Table 6 Concentration index of samples

\begin{tabular}{|c|c|c|c|c|}
\hline \multirow[t]{2}{*}{ Year } & \multicolumn{2}{|c|}{ Self-reported hypertension } & \multicolumn{2}{|c|}{ Tested hypertension } \\
\hline & $\begin{array}{l}\text { Altered } \\
\text { sample }\end{array}$ & $\begin{array}{l}\text { Original } \\
\text { sample }\end{array}$ & $\begin{array}{l}\text { Altered } \\
\text { sample }\end{array}$ & $\begin{array}{l}\text { Original } \\
\text { sample }\end{array}$ \\
\hline 1991 & 0.122 & 0.118 & 0.085 & 0.088 \\
\hline 1993 & 0.156 & 0.144 & 0.000 & -0.003 \\
\hline 1997 & 0.041 & 0.064 & -0.006 & -0.008 \\
\hline 2000 & 0.048 & 0.052 & 0.012 & 0.010 \\
\hline 2004 & 0.111 & 0.110 & 0.023 & 0.031 \\
\hline 2006 & 0.119 & 0.119 & -0.033 & -0.030 \\
\hline 2009 & 0.070 & 0.065 & 0.008 & 0.006 \\
\hline 2011 & 0.030 & 0.032 & -0.025 & -0.024 \\
\hline
\end{tabular}

down. One study found that the prevalence of selfreported hypertension and tested hypertension in 2009 is 12.6 and $29.6 \%$ respectively [42], while the prevalence in our study is 9.46 and $21.07 \%$ respectively. Another study on rural resident aged 35-74 indicates that hypertension prevalence increased by 20\% from 1991 to 2011 [40], however, in our study self-reported prevalence and tested prevalence increased by 6.52 and $4.25 \%$ respectively. This difference suggests that the growth of hypertension prevalence is lower in younger people than in elder people.

Our study also indicates that the prevalence rate of tested hypertension is nearly twice as that of self-reported hypertension; the ratio is lower than previous findings using a national survey [42]. A potential reason is that our results are from rural areas where basic public health services are less developed compare with urban areas and thus the ratio between tested hypertension and selfreported hypertension is a bit less than nationwide area. In other literatures, some researchers did not adopt the definitions of self-reported hypertension and tested hypertension but conducted research on hypertension prevalence and awareness. In a sense, the awareness of hypertension can describe self-reported prevalence.

Based on the uneven access and utilization of health resources, both our findings and prior findings indicate that different measurements of hypertension prevalence vary significantly [43]. Using self-reported hypertension measures implies substantial bias against the real prevalence of hypertension, and thus, the findings based on self-reported measures can be expected to mislead the government's policy. The deviation caused by selfreported measures exists in many countries and is supposed to be higher in low-income and middle-income countries such as China [44].

The main determinants of self-reported hypertension and tested hypertension

Our study indicates that age, BMI, region and marital status are all risk factors for hypertension, which is consistent with prior studies. For instance, in 2011, aging 60 and above shares more than $150 \%$ in the contribution to the concentration indexes of both self-reported prevalence and tested prevalence. BMI and region have significant impacts on hypertension prevalence. Some studies also suggested that income level could have an impact on hypertension prevalence [45], but in our study the impact of income level on the self-reported hypertension and the tested hypertension is respectively insignificant and negative. While many studies suggested that higher education level could reduce the probability of hypertension prevalence [8], our study shows a conflicting result that education level can strikingly affect tested hypertension prevalence, but not self-reported hypertension. The disparity may reflect education can help to improve individuals' health consciousness, which in turn affects the actual control of blood pressure. Additionally, we find people having physical examinations in the past 4 weeks are more likely to get self-reported hypertension but unexpectedly, this result is not so significant for tested hypertension. A possible explanation is that those people who take physical examinations usually have more chances to be diagnosed by doctors and therefore it appears that they have more probability to have selfreported hypertension. More efforts should be put into equalizing basic public health services especially popularizing physical examination as it plays an important role in hypertension awareness and control.

\section{The equity of self-reported hypertension and tested hypertension}

There are both similarities and differences between the findings of our study and prior studies. Some of them have proved that not only hypertension, but also some other chronic diseases are inequitable and pro-poor, such as diabetes and heart diseases [8]. We find that this is also true for tested hypertension. It is generally considered that the poor possess less health resources than the rich and thus suffer a worse health status. However, in our findings, the concentration index of self-reported prevalence is positive, for example, 0.118 [ $95 \% \mathrm{CI}(0.023$, 0.213)] in 1991 and 0.065 [95\%CI $(0.026,0.104)]$ in 2009, which means that self-reported prevalence concentrates on the rich from 1991 to 2011, while the Cs of tested prevalence were negative in some years. This conflicting result might be due to the ignorance of differences in two measurements of hypertension in prior studies. The significant disparities between the rich and the poor, in the access to and utilization of basic health services are taken into consideration for our study. Some researchers shared the same reasoning - it is evident that people in states that provide more education and better medical and health facilities are in a better position to be diagnosed and aware of their own particular illnesses than 
the people in states providing less education and worse medical and health facilities, where there is less awareness of treatable conditions [46].

Combining the equity with the prevalence of the two hypertensions, we can find that the income-related inequality of self-reported prevalence is pro-rich as its concentration indexes and horizontal-inequity indexes are always positive in 8 years. In addition, although the tested prevalence has rapidly increased from 1991 to 2011, the concentration indexes are always close to 0 . This indicates that the prevalence of tested hypertension is less related to income level. This reveals the access to health resources and services in rural China are prorich, even though China is strongly pushing the equalization of basic public health services. There is no doubt that China's basic public health services are getting increasingly equal to everyone and the quantity of health funds has been devoted into basic services such as hypertension screening ever since the equalization policy of basic public health services was carried out. Nevertheless, there still is a gap which cannot be ignored between the poor and rich in health accessibility and utilization. The imbalanced accessibility and utilization of health services might be the cause of the contradictory result in this study and this finding should raise our attention to put more effort into health service equity. Hence, if we focus on self-reported hypertension solely, a biased conclusion or policy will probably come out. Additionally, for the realization of the right to maintain health, China stressed the importance of universal health coverage (UHC) [47]. As a result, in 2011, about $95.7 \%$ of the Chinese population is covered by three main health insurances. In spite of the achievement of UHC, the access to health services and resources is not sufficient yet. Researchers conducted a study to assess the effective coverage of health insurance to explore whether the expansion of health insurance can improve health status [48], while the insufficient access to health services and resources indicated in our study may reveal that the effective coverage of health insurance in rural China is still low. The government may implement relevant policies to promote effective coverage of health services, not only crude coverage.

China has implemented a series of policies to improve the access to health care in rural areas. But current policies cannot sufficiently meet the challenges of promoting effective coverage of health care. Developing social capital in rural area can be a potential solution to promote the management of chronic diseases [49], but systematic measurements have not been well documented yet. It is advisable to establish free health management model in rural China to solve pro-rich access problem. Currently, free physical examination can be received by rural residents. But for those who have been monitored for chronic diseases, free management measures are not provided except outpatient reimbursement for certain kinds of diseases [50]. The feasibility of providing national essential medicines for free in chronic diseases among the elderly has been studied and researchers found that it could be financially guaranteed but a further systematic study is needed [51].

\section{Conclusions}

Our study indicates that there are deviating results between self-reported hypertension and tested hypertension both in prevalence and equity. There are several suggestions proposed by our research. First of all, more efforts should be put into raising the health status of the poor, especially in equal access to health services. Furthermore, adopting self-reported measures solely in research may mislead our policy-making and thus symptom-based measures such as tested hypertension should be adopted more widely in empirical studies.

We acknowledge some limitations in our analysis. The most recent year of our study is 2011 and we have no access to more recent data, thus analysis using data of more recent years are necessary for further study. Another limitation is that in some earlier years of our study such as 1991 and 1993, several independent variables had too few observations and thus were excluded in our regression model. This may result in a minor error of horizontal-inequity index. Lastly, difference between self-reported hypertension prevalence of baseline subjects and new subjects has been proved that have no significance in most years and the Cs of baseline subjects and total subjects have no significant difference, but still there are some potential factors that may affect prevalence and concentration index, although we have tried our best to solve the problem.

\section{Additional files}

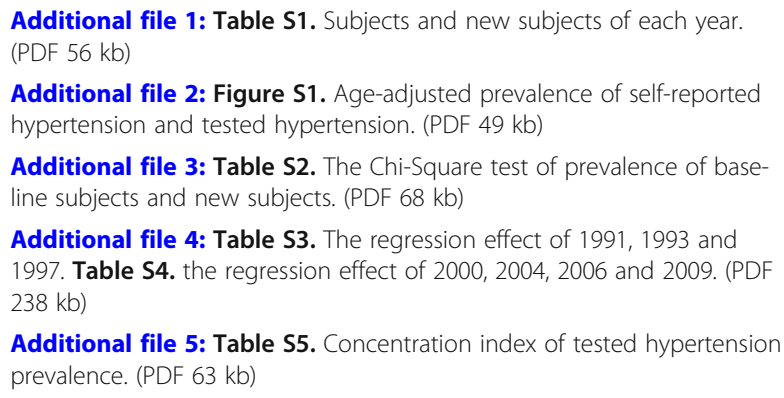

Additional file 2: Figure S1. Age-adjusted prevalence of self-reported hypertension and tested hypertension. (PDF $49 \mathrm{~kb}$ )

Additional file 3: Table S2. The Chi-Square test of prevalence of baseline subjects and new subjects. (PDF $68 \mathrm{~kb}$ )

Additional file 4: Table S3. The regression effect of 1991, 1993 and 1997. Table S4. the regression effect of 2000, 2004, 2006 and 2009. (PDF $238 \mathrm{~kb}$ )

Additional file 5: Table S5. Concentration index of tested hypertension prevalence. (PDF $63 \mathrm{~kb}$ )

Abbreviations

95\% Cl: 95\% Confidence interval; BMI: Body mass index; C: Concentration Index; DBP: Diastolic blood pressure; HI: Horizontal-inequity Index; SBP: Systolic blood pressure 


\section{Acknowledgments}

The authors wish to thank Doctor Nawaz, for his useful comments and language editing which have greatly improved the manuscript. Highly tribute shall be paid to Mr. Bo Li, for his great support and considerable time and effort on the comments of this paper.

\section{Authors' contributions}

DC processed the data and was a major contributor in writing the manuscript ZZ and YS participated in the design this study. XX and CS acquired data and provided administrative support for data analysis. MS, YR and JG was involved in revising the manuscript critically for important intellectual content. XW and $\mathrm{SH}$ offered suggestions to complete this study and made substantial contributions to revised the English of this article. All authors have read and approved the final manuscript.

\section{Funding}

This study was funded by China Medical Board (15-277 and 16-262), National Natural Science Foundation of China (71874137), Shaanxi Social Science Foundation (2017S024), Research Program of Shaanxi Soft Science (2015KRM117), the National high-level talents special support plan (thousands of people plan), Shaanxi provincial youth star of science and technology in 2016. The foundations were not involved in the design of the study or in activities related to data collection and analysis, and manuscript writing. We are thankful to the National Institute of Nutrition and Food Safety, China Center for Disease Control and Prevention, Carolina Population Center, the University of North Carolina at Chapel Hill, the NIH (R01-HD30880, DK056350, and R01-HD38700) and the Fogarty International Center, NIH for financial support for the CHNS data collection and analysis files from 1989 to 2006 and both parties plus the China-Japan Friendship Hospital, Ministry of Health for support for CHNS 2009 and future surveys.

\section{Availability of data and materials}

The datasets generated and analyzed during the current study were derived from the China Health and Nutrition Survey (CHNS) conducted in 2011. They are opened to everyone. Researchers who want to use these data can visit http://www.cpc.unc.edu/projects/china).

\section{Ethics approval and consent to participate}

The ethics approval was obtained by the review board from the University of North Carolina at Chapel Hill, National Institute for Nutrition and Food Safety, China Center for Disease Control and Prevention and China-Japan Friendship Hospital. Informed consent was obtained, and data were anonymized for the analysis.

\section{Consent for publication}

Not applicable.

\section{Competing interests}

The authors declare that they have no competing interests. We declare that Prof. Zhongliang Zhou is a member of the editorial board (Associate Editor) of this journal.

\section{Author details}

'School of Public Policy and Administration, Xi'an Jiaotong University, Xi'an, People's Republic of China. ${ }^{2}$ International Business School Suzhou, Xi'an Jiaotong-Liverpool University, Suzhou, People's Republic of China.

Received: 26 November 2018 Accepted: 23 June 2019

Published online: 01 July 2019

\section{References}

1. Liu Z, Albanese E, et al. Chronic disease prevalence and care among elderly in urban and rural Beijing, China. BMC Public Health. 2009;9(1):1-11.

2. He J, Gu D, Wu X, Reynolds K, Duan X, et al. Major causes of death among men and women in China. N Engl J Med. 2005;353:1124-34.

3. Kearney PM, Whelton M, Reynolds K, et al. Global burden of hypertension: analysis of worldwide data. Lancet. 2005;365(9455):217-23.

4. Ying X, Ke-qin R, Ling XU. Analysis of the economic burden of hypertension in urban and rural households in China. Chin Health Econ. 2010;29(5):69-71.

5. National Health and Family Planning commission of PRC. Health and Family Planning statistical yearbook of China. 2014.
6. Tu S. Socioeconomic inequalities in prevalence and control of hypertension of the rural elderly in Shandong province, China. Master's dissertation. Shandong University; 2009

7. Regidor E, Gutiérrez-Fisac JL, Banegas JR, et al. Association of adult socioeconomic position with hypertension in older people. J Epidemiol Community Health. 2006;60(1):74-80.

8. Dalstra J, Kunst AE, Borrell C, et al. Socioeconomic differences in the prevalence of common chronic diseases: an overview of eight European countries. Int J Epidemiol. 2005;34(2):316.

9. De Gaudemaris R, Lang $T$, Chatellier $G$, et al. Socioeconomic inequalities in hypertension prevalence and care: the IHPAF study. Hypertension. 2002;39(6):1119-25.

10. ZHOU W, HUANG X, YOU C J, et al. Application of antihypertensive drugs and blood pressure control among hypertension population in Jiangxi Province. Chin Gen Pract. 2018;21(22):2729-35.

11. Yang J, Lu F, Zhang C, et al. Prevalence of prehypertension and hypertension in a Chinese rural area from 1991 to 2007. Hypertens Res. 2010;33(4):331-7.

12. Zhaosu $\mathrm{W}$, Yong $\mathrm{H}$, Wen $\mathrm{W}$, et al. Education guidelines for hypertensive patients in China. Chin J Front Med Sci. 2014;6(3):78-98.

13. Fan $G$, Wang $Z$, et al. Prevalence, awareness, treatment and control of hypertension in rural areas in North China in 2013. Zhonghua Yi Xue Za Zhi. 2015;95(8):616.

14. Chen X, Li L, Zhou T, Li Z. Prevalence of hypertension in rural areas of China: a meta-analysis of published studies. PLoS One. 2014;9(12):e115462.

15. Li J, Shi L, Li S, et al. Urban-rural disparities in hypertension prevalence, detection, and medication use among Chinese adults from 1993 to 2011. Int J Equity Health. 2017;16(1):50.

16. Liu $X$, et al. Hypertension prevalence, awareness, treatment, control, and associated factors in Southwest China: an update. J Hypertens. 2017;35(3):637-44.

17. Softič $\mathrm{N}$, et al. Prevalence of chronic diseases among adult Slovene population. Slov J Public Health. 2011;50(3):185-90.

18. Grotto I, Huerta M, Sharabi Y. Hypertension and socioeconomic status. Curr Opin Cardiol. 2008;23(4):335-9.

19. Setiawan Sl, et al. Analysis of socioeconomic status and personal behavior on hypertension in Jakarta, Indonesia: a cross-sectional study. J Comput Theor Nanosci. 2017;23(7):6729-33.

20. Zhang $\mathrm{R}$, et al. Prehypertension and socioeconomic status: a cross-sectional study in Chongqing, China. Clin Exp Hypertens. 2017:39(1):1.

21. Liu S, Ding G, et al. Basic public health services' equalization in Gansu province: a cross-sectional study. Chin Health Qual Manag. 2014;21(5):117-

22. Hou Z, Meng Q, Zhang Y. Hypertension prevalence, awareness, treatment, and control following China's healthcare reform. Am J Hypertens. 2016;29(4):428-31.

23. Yulong T. The reform situation of basic health service equalization problem. Chin Continuing Med Educ. 2016;8(18):27-8

24. Mackebach JP. Differences in the misreporting of chronic conditions, by level of education: the effect on inequalties in prevalence rates. Am J Public Health. 1996:86(5):706.

25. Chrestani MA, Santos IS, Matijasevich AM. Self-reported hypertension: validation in a representative cross-sectional survey. Cad Saúde Pública. 2009;25(11):2395.

26. Vellakkal S, Subramanian SV, Millett $C$, et al. Socioeconomic inequalities in non-communicable diseases prevalence in India: disparities between selfreported diagnoses and standardized measures. PLoS One. 2013;8(7):e68219.

27. Zhang B, Zhai F. The China health and nutrition survey, 1989-2011. NIH public access; 2014. https://doi.org/10.1111/obr.12119.

28. The China Health and Nutrition Survey Database. http://www.cpc.unc.edu/ projects/china/about/proj_desc/survey. Accessed 1 Sept 2018.

29. Popkin BM, Du S, Zhai F, et al. Cohort profile: the China health and nutrition survey-monitoring and understanding socio-economic and health change in China, 1989-2011. Int J Epidemiol. 2009:39(6):1435-40.

30. Zhang B, Zhai FY, Du SF, et al. The China health and nutrition survey, 19892011. Obes Rev. 2014;15:2-7.

31. Xi B, Liang $Y, H e T$, et al. Secular trends in the prevalence of general and abdominal obesity among Chinese adults, 1993-2009. Obes Rev. 2012;13(3):287-96.

32. Wang H, Du S, Zhai F, et al. Trends in the distribution of body mass index among Chinese adults, aged 20-45 years (1989-2000). Int J Obes. 2007;31(2):272. 
33. Wilking SV, Belanger A, Kannel WB, et al. Determinants of isolated systolic hypertension. JAMA. 1988;260(23):3451.

34. Wang Y. Prevent hypertension with mind-body therapy. Gansu Med J. 2013;32(6):428-9.

35. Li N, He H. Multivariate statistical analysis on risk factors of hypertension among the elderly. Chin J Public Health. 1990;6(5):210-2.

36. Kakwani N, Wagstaff A, Van Doorslaer E. Socioeconomic inequalities in health: measurement, computation, and statistical inference. J Econ. 1997; 77(1):87-103.

37. Su M, Si Y, Zhou Z, et al. Comparing the income-related inequity of tested prevalence and self-reported prevalence of hypertension in China. Int J Equity Health. 2018;17(1):82.

38. O'Donnell $\mathrm{O}$, Van Doorslaer $\mathrm{E}$, Wagstaff $\mathrm{A}$, et al. Analyzing health equity using household survey data : a guide to techniques and their implementation. World Bank. 2008:86(10):816.

39. Vellakkal $S$, Millett $C$, et al. Are estimates of socioeconomic inequalties in chronic disease artefactually narrowed by self-reported measures of prevalence in low-income and middle-income countries? Findings from the WHO-SAGE survey. J Epidemiol Community Health. 2015;69(3):218.

40. Wang J, ning X. Trends of hypertension prevalence, awareness, treatment, and control in rural areas of northern China during 1991 to 2011. J Hum Hypertens. 2014;28:25-31.

41. Hall J E, da Silva A A, do Carmo J M, et al. Obesity-induced hypertension: role of sympathetic nervous system, leptin, and melanocortins. J Biol Chem. 2010;285(23):17271-6.

42. wang J, Zhang L, et al. Prevalence, awareness, treatment and control of hypertension in China: results from a national survey. Am J Hypertens. 2014; 27(11):1355.

43. Li H, Meng Q. Prevalence, awareness, treatment, and control of hypertension in rural China: results from Shandong Province. 2010;28(3):432-8.

44. Zhan Y. Health inequality and its measurement-a literature review. World Econ Papers. 2009;(3):109-19.

45. Graham H. Understanding health inequalities. McGraw-Hill Education; 2009

46. Sen A. Health: perception versus observation: self reported morbidity has severe limitations and can be extremely misleading. Bmj British Medical Journal. 2002;324(7342):860.

47. Marten $\mathrm{R}$, et al. An assessment of progress towards universal health coverage in Brazil, Russia, India, China, and South Africa (BRICS). Lancet. 2014;384(9960):2164-71.

48. $\mathrm{Ng} \mathrm{M}$, et al. Effective coverage: a metric for monitoring universal health coverage. PLoS Med. 2014;11(9):e1001730.

49. Minghui W, et al. A dicussion on the matter of the chronic disease management of peasants in the backdrop of the new rural cooperative medical system. Chin Health Serv Manage. 2013;30(4):283-4.

50. Dai BZ. Analysis on the current dilemma and cause of chronic disease management in rural China. Chin J Public Health Manag. 2017:33(4):38-41.

51. Yuan X, Xiaoli F, et al. Economic feasibility study on providing National Essential Medicine for free in chronic disease among elderly in rural areas. J Med Forum. 2018;39(05):74-6.

\section{Publisher's Note}

Springer Nature remains neutral with regard to jurisdictional claims in published maps and institutional affiliations.

Ready to submit your research? Choose BMC and benefit from:

- fast, convenient online submission

- thorough peer review by experienced researchers in your field

- rapid publication on acceptance

- support for research data, including large and complex data types

- gold Open Access which fosters wider collaboration and increased citations

- maximum visibility for your research: over $100 \mathrm{M}$ website views per year

At $\mathrm{BMC}$, research is always in progress.

Learn more biomedcentral.com/submissions 